Khub Singh

D. Singh

P. Kumar

\section{Dark coat color in Indian desert goats as an adaptation mechanism to economize feed energy in cool period}

\section{Ökonomie der Nahrungsenergie in Kälteperioden}

Black coat absorbs 80 per cent of solar radiation impinging on its fur in contrast to only 40 per cent by white coats. It might be predicted, therefore, that white and light color could be the predominant color of goats in areas of high solar radiation incidence. In the sub-tropical desert areas the goats are, however, predominantly black. Obviously, to assess the role of black color in desert goats, the entire climatic cycle to which animal is exposed assumes significance. During short spell of 2-3 months cool period in the deserts not only the minimum ambient temperature touches freezing point but the sparse vegetation also becomes scarce.

It was, thus, hypothesized that the predominance of dark color of loose and shaggy coat in desert goats may be an adaptation for energy economy during the cool period. The use of radiant energy in reducing energy expenditure for thermoregulatory needs during cool period was studied. The daily gain in live weight was higher in weaned kids receiving $8 \mathrm{~h}$ daily exposure to solar radiation than their contemporaries kept inside a shed. The difference in daily live weight gain between the kids of two groups was more in black and dark tan coloured kids than kids with white coloured coat.

Feed conversion efficiency was also better in kids exposed to solar radiation than housed inside the shed. Resting metabolic rate per $\mathrm{kg}$ of metabolic body weight per hour was lower in kids exposed to solar radiation than those not exposed to solar radiation. Lower metabolic rate and better feed conversion efficiency explained utilization of solar energy for thermoregulatory needs in cool period and there by saving some feed energy for higher growth rate.
Khub Singh - D. Singh $\cdot$ P. Kumar

Central Institute for Research on Goats

Makhdoom

P.O. Farah-281

122 Mathura (U.P.)

India 